\title{
A case of bronchial aspiration: the importance of early diagnosis and clinical suspicion
}

\author{
*David P Ripley, Andrew K Henderson
}

Department of General Medicine, Lorn \& Islands District General Hospital, Oban, Scotland, UK

Received 7th September 2006; accepted 24th February 2007

\begin{abstract}
Summary
We present a case of foreign body aspiration, the diagnosis of which was delayed until two months after the event. This case highlights the importance of a detailed clinical history in establishing the diagnosis of aspiration and how this was complicated by direct visualisation via bronchoscopy which suggested a possible diagnosis of bronchial carcinoma. Subsequent histological analysis confirmed a diagnosis of Brazil nut aspiration, which ultimately required surgical extraction through a rigid endoscope.

(C) 2007 General Practice Airways Group. All rights reserved.

DP Ripley and AK Henderson. Prim Care Resp J 2007; 16(3): 191-193.

doi:10.3132/pcrj.2007.00029
\end{abstract}

Keywords foreign body aspiration, diagnosis, bronchoscopy, histological examination

\section{Introduction}

Foreign body aspiration, although more common in children than adults, can occur at any age. ${ }^{1}$ Bronchial aspiration typically presents as an acute and sometimes life-threatening event. On occasions, however, it may manifest itself insidiously, resulting in non-specific symptoms and a difficult diagnosis. We present a case of foreign body aspiration, the diagnosis of which was delayed for two months and which required biopsy and histological analysis for confirmation.

\section{Case report}

A 61 year-old gentleman was referred by his general practitioner (GP) to the Medical Outpatient Clinic with a twomonth history of persistent cough with white sputum production, malaise, lethargy and sweats. He had been previously well with no other medical history apart from asthma as a child. He was a life-long non-smoker, drank no alcohol, and worked as a Church Minister. Antero-posterior (AP) and lateral chest radiographs revealed changes consistent with right middle lobe consolidation and lobar collapse (Figures 1 and 2). Of interest, he had previously attended his GP one month earlier when a chest radiograph was reported as being normal (Figure 3); however, on subsequent review of the films there was evidence of some hazy opacification in the right lower zone. Further detailed questioning revealed that his symptoms had started shortly after choking on a Brazil nut. He was provisionally diagnosed with a persistent cough secondary to a foreign body aspiration. Bronchoscopy was arranged for visualisation and retrieval.

Bronchoscopy revealed white homogeneous necrotic tissue completely obstructing the right intermediate bronchus (Figure 4), which could not be removed by Dornier basket. Given the suspicious appearance of the lesion, suggestive of a bronchial carcinoma, biopsies were sent for histolopathological analysis. Analysis confirmed that the material was a fibrinopurulent exudate mixed with foreign material of a vegetable nature, confirming the clinical suspicion of an endobronchial foreign body.

Computed Tomography (CT) scan of the chest at the time of bronchoscopy identified mild concentric thickening around the right intermediate bronchus and patchy consolidation in the right mid and lower lobes. There was no evidence of malignancy on the CT scan.

The patient was referred to the Cardiothoracic surgery team for surgical extraction of the nut particle, which was achieved with some difficulty under general anaesthetic via a

* Corresponding author: 30 Bridge Street, Penicuik, Midlothian, EH26 8LN, Scotland, UK

Tel: +44 (0)1968 675475 Email: davidripley@blueyonder.co.uk 
Figure 1. AP chest X-ray at the medical outpatient clinic two months after aspiration.

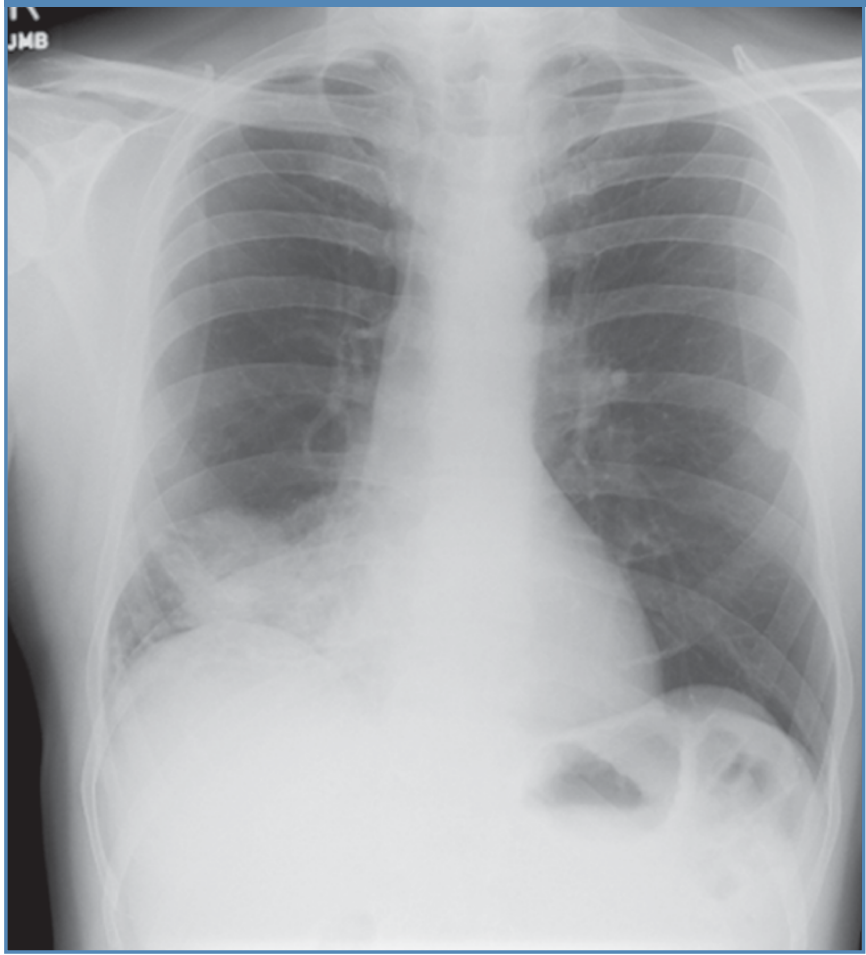

Figure 3. CXR on initial presentation to the General Practitioner one month after aspiration.

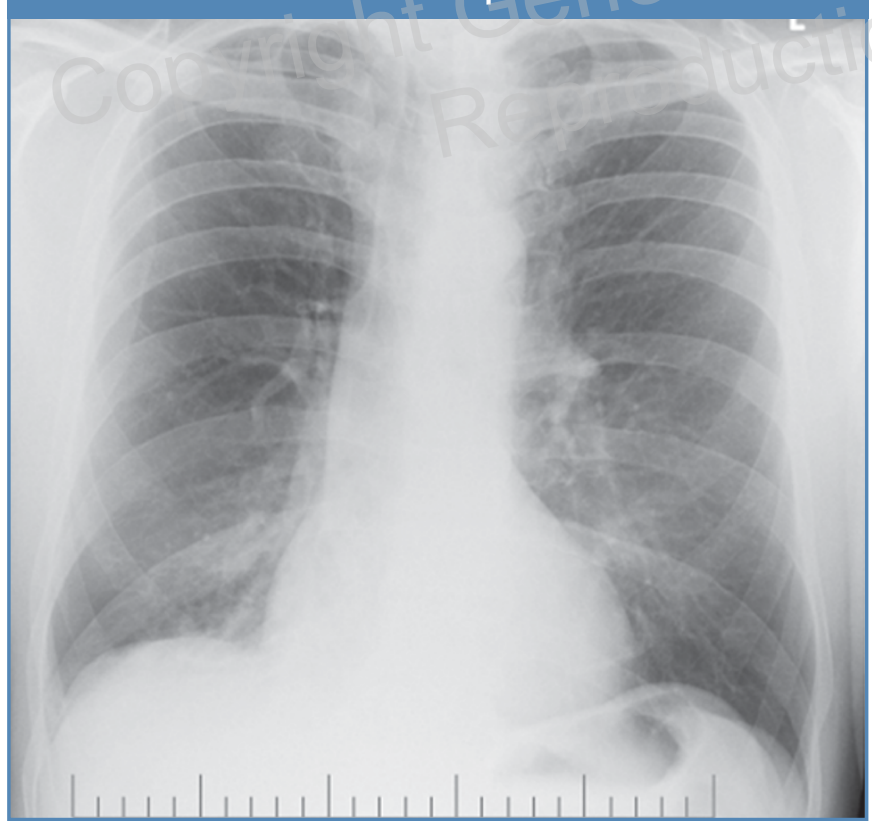

rigid bronchoscope. The nut was eventually removed piecemeal with large biopsy forceps.

\section{Discussion}

Bronchial aspiration of foreign bodies may occasionally manifest insidiously. Small foreign bodies are able to lodge in

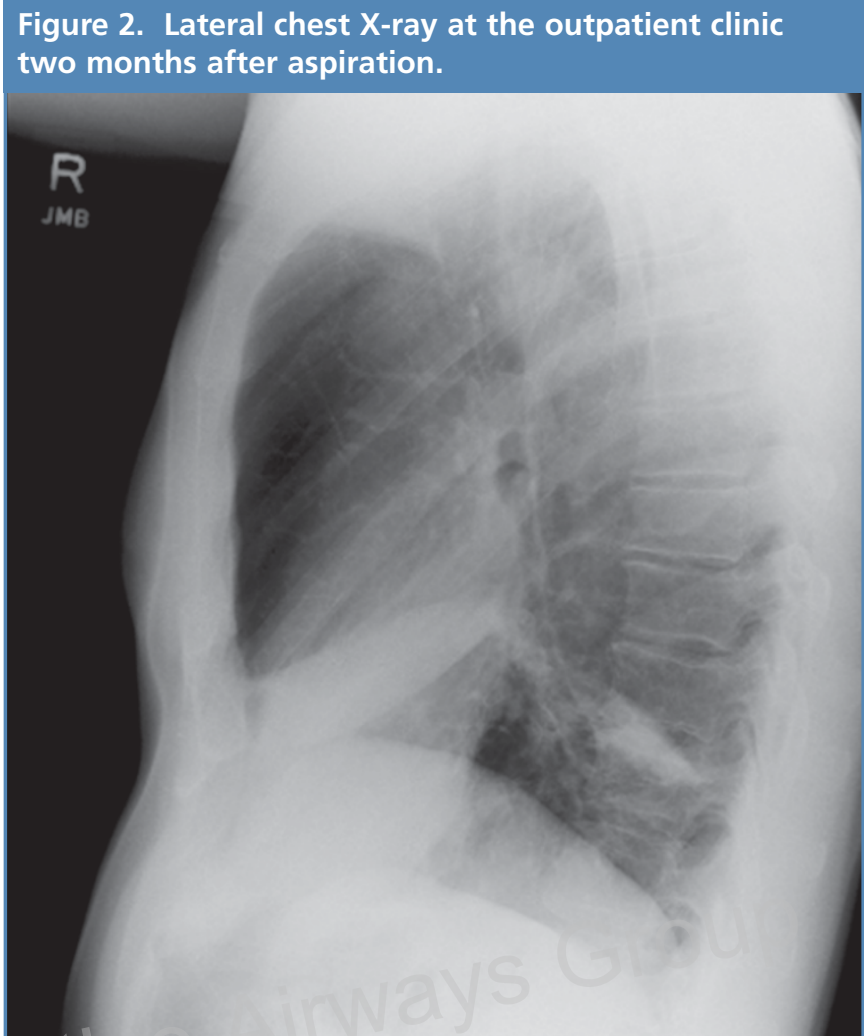

Figure 4. Right intermediate bronchus view during flexible bronchoscopy.

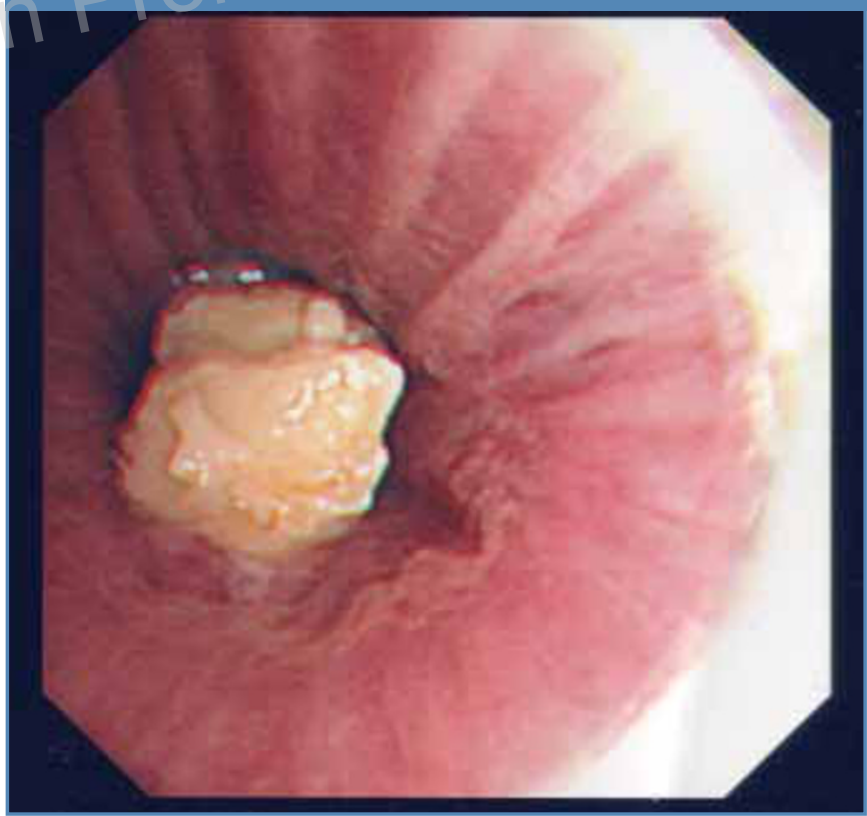

the lobar or even segmental bronchus. This can result in nonspecific symptoms which may imitate other lung diseases such as bronchial asthma or chronic obstructive pulmonary disease (COPD). ${ }^{2}$ Silent aspiration can also present with significant sequelae such as haemoptysis, abscess formation or pneumonia; ${ }^{3}$ indeed, this has been shown to play a particularly 
important role in the pathogenesis of pneumonia in elderly patients. $^{4}$

Early detection and removal of the foreign body usually results in rapid resolution of the symptoms. Chest radiography should be performed routinely in suspected foreign body aspiration. Since over $90 \%$ of foreign bodies are radiolucent, a normal chest radiograph - as was obtained on this patient does not exclude aspiration, and a high index of suspicion is required. ${ }^{5}$ Flexible bronchoscopy is the gold standard for the detection of aspirated foreign bodies, allowing successful removal in most cases $^{6}$ - although on occasions instrumentation may have limitations in removing a firmly adherent or large foreign body. Endoscopic laser therapy ${ }^{7}$ and cryotherapy $^{8}$ have both been suggested as tools to destroy granulation tissue and resect foreign bodies in such cases.

This case illustrates how, despite direct imaging with flexible bronchoscopy, a diagnosis was only established after microscopic analysis of the specimen. It also demonstrates that early detection is important. Delayed diagnosis on this occasion resulted in the specimen not being removed at bronchoscopy due to chronic inflammation and adherence of the foreign body to the bronchial wall, so that it ultimately required surgical extraction.

\section{Conflict of interest declaration}

None declared

\section{References}

1. Baharloo F, Veyckemans F, Francis $C$ et al. Tracheobronchial foreign bodies: presentation and management in children and adults. Chest 1999;115(5): 1357-62.

2. Chen $\mathrm{CH}$, Lai $\mathrm{CL}$, Tsai $\mathrm{TT}$ et al. Foriegn body aspiration into the lower airway in chinese adults. Chest 1997;112(1):129-33.

3. Al-Majed SA, Ashour M, Al-Mobeireek AF et al. Overlooked inhaled foreign bodies: late sequelae and the likelihood of recovery. Resp Medicine 1997;91: 293-6.

4. Kikuchi $\mathrm{R}$, Watabe $\mathrm{N}$, Konno $\mathrm{T}$ et al. High incidence of silent aspiration in elderly patients with community-acquired pneumonia. Am J Resp Crit Care Med 1994;150:251-3

5. Jhamb U, Sethi GR, Puri R et al. Surgical Emphysema: A rare presentation of foregin body inhalation. Pediatric Emergency Care 2004;20(5):311-13.

6. Yilmaz A, Akkaya E, Damadoglu E et al. Occult bronchial foreign body aspiration in adults: analysis of four cases. Respirology 2004;9(4):561-3.

7. Hayashi AH, Gillis DA, Bethune DA et al. Management of foreign body bronchial obstruction using endoscopic laser therapy. J Pediatric Surgery 1990; 25:1174-6.

8. Roden S, Homasson JP. A new use for intrabronchial cryotherapy: extraction of foreign bodies. Presse Med 1989;18:897S.

Available online at http://www.thepcrj.org 